\title{
Reseña del libro Hacia una formación disruptiva de los docentes. 10 claves para el cambio
}

Actuar disruptivamente en términos de formación docente nos imprime el desafío de observar, tomar conciencia, buscar los puntos de ruptura necesarios, orientarnos y cambiar.

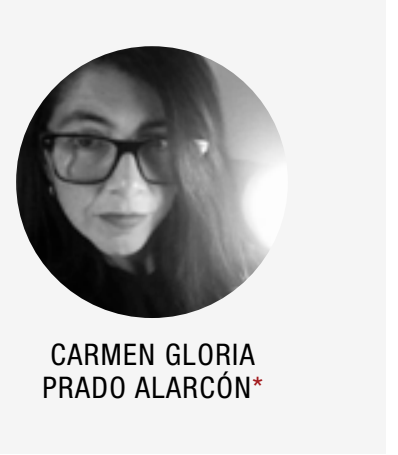

El libro escrito por Carlos Marcelo y Denisse Vaillant es una motivación a repensar la formación inicial y continua del docente del siglo XXI. Los autores, investigadores con una vasta experiencia académica en el desarrollo profesional docente, nos proponen que, "para transformar la formación docente es necesario reconocer y comprender los casos de ruptura con el paradigma tradicional" (Marcelo y Vaillant, 2018, p. 9).

Carlos Marcelo es doctor en Ciencias de la Educación y coordinador del programa de doctorado en Educación de la Universidad de Sevilla. Denisse Vaillant, doctora en Educación por la Université de Québec y Magister en planeamiento y gestión educativa por la Université de Genève, es directora del programa de doctorado en Educación del Instituto de Educación de la Universidad ORT de Uruguay.

El texto está organizado en 10 capítulos, cada uno de los cuales corresponden a componentes claves de la formación docente. El título y estructura de los capítulos dan cuenta de la tensión que, a juicio de los autores, existe entre la tradición y la necesidad de innovación en cuanto a la formación inicial y continua docente. En cada capítulo, bajo el subtítulo "Ideas inspiradoras para la formación", los autores exponen ejemplos que movilizan hacia la innovación.

En el primer capítulo titulado Una formación centrada en lo local versus apertura al mundo, los autores reflexionan acerca de la necesidad de concebir y orientar la formación docente tanto inicial como continua desde una perspectiva global e internacional. Observan que, aunque en la actualidad prima un discurso importante en torno a la globalización y la necesidad de internacionalización, la formación docente permanece centrada en lo local siendo muy pocas las propuestas de formación que integran la dimensión global, internacional e intercultural en su oferta académica. El capítulo esclarece los conceptos de internacionalización y globalización y profundiza al presentar la internacionalización como una estrategia, ya que "ofrece oportunidades para enriquecer los marcos de referencias de los futuros docentes y afianzar los valores culturales locales en relación con las dinámicas mundiales" (Marcelo y Vaillant, 2018, p. 13). Esto posibilita, entre otras cosas, desarrollar competencias interculturales, efectuar aprendizajes complejos, mejorar la comprensión de áreas disciplinares y el pensamiento crítico.

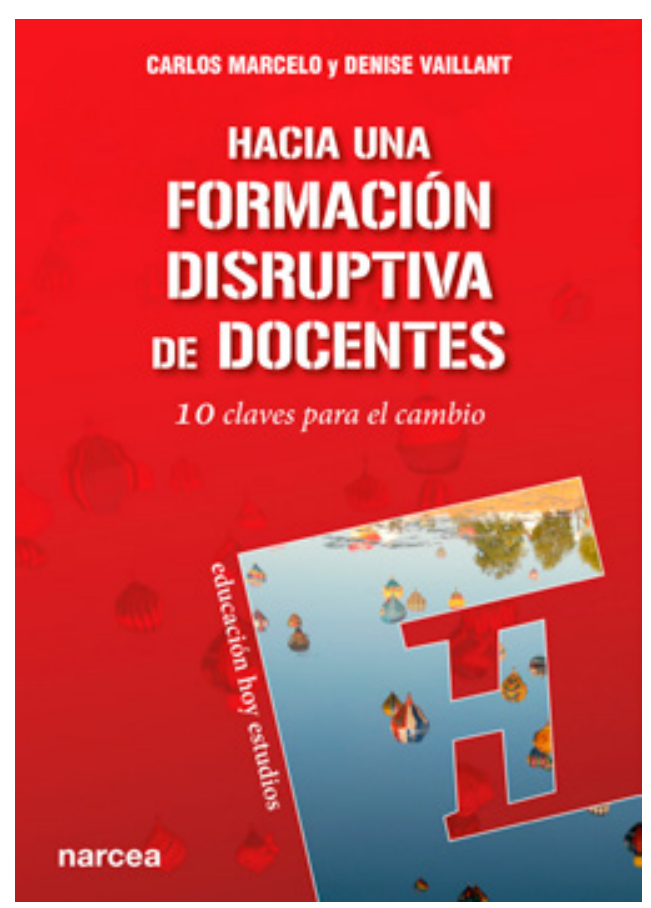

\footnotetext{
* Psicopedagoga. Licenciada en Educación. Magister en gestión de políticas de educación y cultura. Coordinadora de Formación e Innovación del Centro de Desarrollo Profesoral de la Pontificia Universidad Católica Madre y Maestra. Para contactar a la autora: carmenprado@ pucmm.edu.do, https://cl.linkedin.com/in/carmengloriaprado
}

ISSN (en línea): 1814-4152 / Sitio web: http://cuaderno.pucmm.edu.do Cuaderno de Pedagogía Universitaria, Vol. 16, n. ${ }^{\circ} 32$, julio-diciembre, pp. 109-111 
Finalmente, los autores exponen diferentes modalidades que pueden ser utilizadas para potenciar este tipo de formación.

En el segundo capítulo, bajo el título Estructuras formales versus la informalidad en el aprendizaje, se distinguen las diferencias entre aprendizaje formal e informal y se enfatiza en la necesidad de reconocer y favorecer procesos informales de aprendizaje, aprendizaje por medio de la experiencia y autoformación. Se reconoce que la formación de hoy es un proceso complejo y dinámico que va más allá de las clases presenciales establecidas en el currículo y que implica necesariamente emplear modelos y estrategias comprometidos con la autonomía, la autorregulación, el uso de métodos formales e informales para que los estudiantes y docentes actualicen en forma permanente sus competencias y capacidades. En este sentido, cobran relevancia el empleo de metodologías como las de aprendizaje orientado a proyectos (AOP) y aprendizaje basado en problemas (ABP), las que sitúan al aprendiz en contextos donde se requiere investigar, tomar decisiones y proponer una solución. Se enfatiza en la importancia de que las experiencias prácticas posean calidad e incidan en el proceso de aprendizaje a través de una ordenación paulatina y creciente, la conexión de la experiencia con marcos conceptuales y la incorporación de procesos de reflexión y análisis.

El tercer capítulo, Formación basada en el docente versus centrada en el aprendizaje profundiza en el cuestionamiento existente en la actualidad hacia los programas de formación percibidos como frontales, fragmentados y academicistas, en los cuales poca o ninguna relación existe entre lo que se aprende y lo que realmente ocurre en el aula. A juicio de los autores, es necesario caminar hacia una formación docente centrada en el alumno. Para ello es clave formar al docente en el uso de instrumentos y datos que le permitan validar los efectos de su intervención pedagógica en el aprendizaje de sus estudiantes y, en consecuencia, tomar decisiones con base en evidencias. Avalan esta premisa diversos estudios efectuados sobre la efectividad de maestros formados desde una visión centrada en el alumno junto con investigaciones relativas a las fuentes de satisfacción expresadas por los docentes en las que sobresale el "logro de los aprendizajes" como una de las principales. Los autores destacan la experiencia de Finlandia, que como país ha orientado la formación docente hacia la investigación encontrándose en la currícula, tanto de formación inicial docente como a nivel de maestría, aproximadamente un 20\% dedicado a la investigación, además de la obligatoriedad para la obtención del título de la realización de una tesis basada en un proyecto de investigación.

En el cuarto capítulo Ruta única para la formación versus diversidad de caminos, se expone que si bien la ruta de formación tradicional y mayormente utilizada para la formación docente ha sido la de programas en universidades y centros especializados, se aprecia el surgimiento de rutas alternativas para preparar docentes con el objeto de suplir necesidades del sistema educativo o bien como respuesta a las debilidades de la formación inicial. Se describen interesantes programas impulsados por gobiernos, propuestas con apoyo filantrópico y estrategias particulares que constituyen rutas alternativas. A juicio de los autores, estas rutas alternativas a la formación inicial suponen una llamada de atención acerca de la necesidad de revisar y flexibilizar aspectos que se han consolidado como normales en la formación docente, por lo cual concluyen que se necesita innovación tanto en su estructura como en sus métodos.

En el quinto capítulo Conocimiento disciplinar versus capacidad de enseñar, se insta a superar el divorcio entre las materias disciplinares y las pedagógicas presentes en los planes de estudio. Señalan los autores que es esta fragmentación la que lleva a situaciones tan paradójicas como que el docente conozca los conceptos de la disciplina y la pedagogía, pero tenga dificultades para integrarlos y aplicarlos en situaciones de práctica o en el ejercicio de su profesión. Se describen en el capítulo iniciativas abordadas por universidades a nivel mundial que van desde colocar la práctica en el centro del currículo hasta emplear actividades de simulación, grabaciones, círculos de aprendizaje, entre otras.

En el sexto capítulo Primacía de lo cognitivo versus la dimensión socioemocional, se propone que los procesos de formación inicial y continua de los docentes integren la reflexión acerca de las creencias y pensamientos de los profesores, considerando la dimensión emocional de la docencia. Un modelo útil en este sentido, referido por los autores, es el propuesto por Korthagen (2014 y 2016) quien plantea un sistema de reflexión y análisis acerca de situaciones de enseñanza a partir de diferentes niveles de interacción del docente, que incluyen desde elementos contextuales hasta elementos vinculados con su propia identidad personal y profesional. 
En el séptimo capítulo Estrategias basadas en lo individual versus escenarios colectivos, los autores hacen referencia a diversos informes internacionales que permiten concluir que la formación docente se organiza en torno a estrategias en las cuales priman la participación individual del docente sobre la participación en redes profesionales. Trabajos desarrollados por los autores en años anteriores demuestran que la formación y desarrollo profesional docente necesitan de entornos en los que se favorezca la colaboración y el aprendizaje entre iguales. Los autores destacan algunas estrategias que favorecen el trabajo colaborativo entre los docentes y que permiten desarrollar aprendizajes compartidos y, paulatinamente, constituir equipos de trabajo. Se presentan experiencias aplicadas en esta dirección por Japón, Singapur, España y Chile.

En el octavo capítulo Formador en solitario versus capacidades que suman, los autores invitan a reflexionar respecto del perfil y el rol de los formadores de docentes como modelos de quienes desempeñan el oficio de enseñar. Se observa que, tanto en informes internacionales como hacedores de políticas insisten en la necesidad de seleccionar y preparar a los formadores de docentes y delimitar con claridad su rol. También se expone el desafío de avanzar en el desarrollo de una pedagogía para la formación docente, ya que a juicio de los autores

el modelamiento en la formación de maestros y profesores no solo consiste en enseñar a los docentes rutinas y prácticas a desarrollar en el aula. Se refiere también a la reflexión acerca de valores y actitudes: tiene que ver con hacer explícitos los propósitos de la formación, de forma que los futuros docentes vean cómo sus formadores transforman su enseñanza en formas y prácticas docentes que pueden mejorar el aprendizaje significativo para los estudiantes (Marcelo y Vaillant, 2018, p. 72).

En el noveno capítulo Instituciones uniformes y rígidas versus estructuras flexibles, se insiste en la necesidad de conformar instituciones flexibles con espacios acondicionados para la formación. Los autores observan, a partir de estudios, cómo hoy la rigidez y homogeneización sostenida por instituciones de formación docente persisten y son a veces impulsadas por la loable necesidad de mantener estándares y aplicar normativas vigentes. Se presenta entonces la discusión entre la necesaria homogeneización de los procesos formativos de docentes para asegurar el cumplimiento de estándares de calidad y la también necesaria diversidad de ofertas de formación que reflejen la realidad y den repuesta creativa. Por otra parte, en términos arquitectónicos, se aprecia en los centros de formación una distribución de los espacios que refleja y mantiene una cultura que valora la privacidad y soledad del trabajo docente y desfavorece la colaboración entre maestros. Se exponen en este capítulo las experiencias impulsadas por Finlandia, Suecia y Dinamarca que rompen con estos paradigmas y proponen soluciones creativas.

En el décimo capítulo Tecnologías reproductoras versus tecnologías para el cambio, los autores expresan que hoy urge el uso de tecnologías transformadoras, la utilización de situaciones de aprendizaje tanto físico como digitales y la combinación de formación sincrónica y asincrónica. Los autores se preguntan cómo se puede superar el divorcio que observamos en la actualidad entre las tecnologías y las prácticas de enseñanza en la formación docente. Para dar respuesta, exponen algunos modelos como el TPCK de Koehler y Mishra (2008).

El libro Hacia Una formación disruptiva de los docentes, 10 claves para el cambio permite reflexionar acerca de importantes componentes de la formación docente tanto inicial como continua. A través de las investigaciones ofrecidas otorga elementos de juicio y fundamentos respecto a la necesidad de cambio y disrupción. Contiene una pertinente selección de modelos y experiencias de formación empleados a nivel mundial que pueden ser utilizados como referentes. El enfoque del texto puede ser de utilidad tanto para hacedores como gestores de políticas de educación, decanos y directores de escuelas de educación, gestores a cargo de la formación profesoral en educación superior, especialistas curriculares, administradores y supervisores de educación escolar, profesores y académicos preocupados por su formación continua.

Este libro puede convertirse con facilidad en una guía que permite la revisión y análisis de los planes de formación docente tanto inicial como continúa. Al hacer este ejercicio desde una actitud honesta y crítica, podríamos visualizar con claridad si nuestros programas de formación están más cerca de la tradición o de la innovación. Actuar disruptivamente en términos de formación docente nos imprime el desafío de observar, tomar conciencia, buscar los puntos de ruptura necesarios, orientarnos y cambiar. - 